DOI: 10.17707/AgricultForest.61.4.37

\author{
Enver KENDAL, Yusuf DOĞAN
}

\title{
STABILITY OF A CANDIDATE AND CULTIVARS (Hordeum vulgare L) BY GGE BIPLOT ANALYSIS OF MULTI-ENVIRONMENT YIELD TRIAL IN SPRING BARLEY
}

\begin{abstract}
SUMMARY
The explication of candidate line and new varieties is uncomfortable the affect of genotype-by-environment interaction (GEI). The AMMI (Additive main effects and multiplicative interaction) analysis and GEI is making to estimation grain yield and understands GxE interaction patterns by researches as differential ranking of variety yields in multi-environment trials. So, a candidate of release and three spring barley varieties which registered in different years were reclaimed at seven environments. The experiments were performed according to a complete randomized block design with four replications. The stability and superiority of genotypes for yield was determined using AMMI and GGE biplot analysis. Factors (G, GE, and GEI) were found to be highly significant $(P<0.01)$ for grain yield. AMMI analysis indicated that the major contributions to treatment sum of squares were environments (79.4\%), GE (13.9\%) and genotypes (6.4\%), respectively, suggesting that grain yield of genotypes were effected environmental conditions. The GGE biplot indicated that PCA 1 and PCA 2 axes (Principal component) were significant as $\mathrm{P}<0.01$ and supplied to 86.3\% of the complete GxE interaction. The GGE biplot indicated that four mega-environment were occured in terms of varieties. The varieties and candidate line took part in an independent mega-environment. On the other hand, Candidate line showed general adaptability (E1, E2, E4, E5 and E7), while Altikat and Sur 93 showed specific adaptation to E3 and E6 respectively. According to both techniques, especially Sahin 91, Sur 93 and Altikat came forward with low yielding, while candidate line with high yielding, stability and general adaptability. Statistical results indicated that AMMI and GGE biplot are informative techniques to compare varieties with candidate lines to discover general stability, adaptation pattern for practical recommendations.
\end{abstract}

Keywords: Barley, GEI, AMMI, GGE biplot, grain yield, stability.

\section{INTRODUCTION}

Barley (Hordeum vulgare L.) is important for feed grain, fall and winter pasture, and forage cereal crop of Turkey and accounted for nearly $20 \%$ of the

\footnotetext{
${ }^{1}$ Enver Kendal (corresponding author: enver21_1@hotmail.com), Yusuf Doğan, Department of Crops and Animal Production, Kizıltepe Vocational Training High School, Artuklu University, Kizıltepe, Mardin, TURKEY.

Paper presented at the $6^{\text {th }}$ International Scientific Agricultural Symposium "AGROSYM 2015".

Note: The authors declare that they have no conflicts of interest. Authorship Form signed online.
} 
total cereal production. Barley has been cultivated for many years and has a wide range of adaptation, growing best on fertile, well-drained soils in Shout -Eastern Anatolia. It is also grown mainly on rainfall conditions, but genotype $\mathrm{x}$ environment interaction (GEI) restricts the progress in yield improvement under rain fed and unpredictable climatic conditions (Kiliç, 2014). Therefore, GxE interaction is of major importance, because of provides information about the effect of test environments on genotype performance and plays an important key role for assessment of performance yield stability of the breeding genotype (Mohammadi et al. 2013). Increasing genetic gain in yield performance is possible in part from narrowing the adaptation of genotypes and so maximizing yield in particular environments are described by GE interaction (Sabaghnia et al. 2012).Grain yield is highly affected by many genetic factors as well as environmental fluctuations; because it is a complicated marker which is depend on somewhat other markers (Akter et al. 2014). However, the G x E interaction is significant appearance for breeding program and interaction of genotypes (Sayar and Han, 2015). The major objective of study reveal adaptation of barley genotypes using AMMI and GGE biplot analysis to estimate the importance of GE interaction on yield, define mega-environments, identity the best acting genotype for every mega-environment and testing promising line under across environments and compare with new and old varieties to estimate stability and performance for practical recommendations.

\section{MATERIAL AND METHODS}

Plant genetic materials: The experimental material comprising candidate line, one new and two old barley varieties (Table 1) were evaluated in seven rainfed environments (Diyarbakır, Hazro, Adiyaman and Ceylanpınar) in 2011-12 and 2013-14 growing seasons(Table 2). The experiment was conducted in a randomized block design with four replications. The seeding rate was used 450 seeds $\mathrm{m}^{-2}$. Plot size was $7.2 \mathrm{~m}^{-2}(1.2 \times 6 \mathrm{~m})$ consisting of 6 rows spaced $20 \mathrm{~cm}$ apart. Sowing was done by Wintersteiger drill. The fertilization rates for all plots were used $60 \mathrm{~kg} \mathrm{~N} \mathrm{ha}^{-1}$ and $60 \mathrm{~kg} \mathrm{P} \mathrm{ha}^{-1}$ with sowing time and $60 \mathrm{~kg} \mathrm{~N} \mathrm{ha}^{-1}$ was applied to plots at the early stem elongation. Harvest was done using Hege 140 harvester up on $6 \mathrm{~m}^{2}$.

Table 1. The information's about varieties, used in experiment

\begin{tabular}{|l|l|c|c|c|}
\hline Name & Pedigree of cultivar & Origin & $\begin{array}{c}\text { Approved year and } \\
\text { institution }\end{array}$ & $\begin{array}{c}\text { Spike } \\
\text { rows }\end{array}$ \\
\hline Candidate & AK-115 WUR04 & NETHERLANDS & $\begin{array}{c}2012 \\
\text { GAPIARTC }\end{array}$ & 2 \\
\hline Altikat & $\begin{array}{l}\text { Arta/4/Arta/3/Hml- } \\
\text { O2//Esp/1808-4L } \\
\text { ICB96-0601-0AP-10AP-0AP }\end{array}$ & ICARDA & $\begin{array}{c}2011 \\
\text { GAPIARTC }\end{array}$ & 6 \\
\hline Sur 93 & YEA- Eskişehir & TURKEY & $\begin{array}{c}1993 \\
\text { GAPIARTC }\end{array}$ & 2 \\
\hline Sahin 91 & YEA 1553-1/Eskişehir & TURKEY & $\begin{array}{c}1993 \\
\text { GAPIARTC }\end{array}$ & 2 \\
\hline
\end{tabular}

GAPIARTC: GAP International Agricultural Research and Training Center 
Table 2. Years, sites, codes, coordinate status of environment long term of precipitation

\begin{tabular}{|c|c|c|c|c|c|c|}
\hline Years & Sites & $\begin{array}{c}\text { Code of } \\
\text { sites }\end{array}$ & $\begin{array}{c}\text { Altitude } \\
\text { (m) }\end{array}$ & Latitude & Longitude & $\begin{array}{c}\text { Annual } \\
\text { rainfall (mm) }\end{array}$ \\
\hline \multirow{3}{*}{ 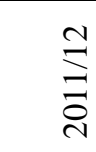 } & Diyarbakir & E1 & 496 & $36^{\circ} 97^{\prime} \mathrm{N}$ & $38^{\circ} 42^{\prime} \mathrm{E}$ & 680.6 \\
\hline & Hazro & E2 & 895 & $38^{\circ} 15^{\prime} \mathrm{N}$ & $40^{\circ} 49^{\prime} \mathrm{E}$ & 743.9 \\
\hline & Adiyaman & E3 & 483 & $37^{\circ} 46^{\prime} \mathrm{N}$ & $40^{0} 56^{\prime} \mathrm{E}$ & 592.0 \\
\hline \multirow{4}{*}{ 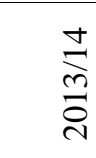 } & Diyarbakir & E4 & 496 & $36^{\circ} 97^{\prime} \mathrm{N}$ & $38^{\circ} 42^{\prime} \mathrm{E}$ & 356.7 \\
\hline & Hazro & E5 & 895 & $38^{\circ} 15^{\prime} \mathrm{N}$ & $40^{\circ} 49^{\prime} \mathrm{E}$ & 743.9 \\
\hline & Adiyaman & E6 & 685 & $37^{\circ} 46^{\prime} \mathrm{N}$ & $40^{0} 56^{\prime} \mathrm{E}$ & 592.0 \\
\hline & Ceylanpinar & E7 & 363 & $36^{\circ} 51^{\prime} \mathrm{N}$ & $40^{\circ} 20^{\prime} \mathrm{E}$ & 260.3 \\
\hline
\end{tabular}

Statistical analysis: The data grain yields of twelve (12) genotypes in seven (7) environments were evaluated by AMMI analysis (Gauch, 1988). The AMMI and GGE biplots were used to identify the mega- environments and superior genotypes. All statistical analyses were performed using GenStat Release 14.1 (Copyright 2011, VSN International Ltd.) and GGE biplot software programs.The data were graphically analyzed for interpreting GE interaction using the GGE biplot software (Yan 2001). GGE biplot methodology is composed of the biplot concept (Gabriel 1971) and GGE concept (Yan et al 2000).

\section{RESULTS AND DISCUSSION}

The variance of AMMI analysis showed that as $\mathrm{p}<0.01$, all factors had significant effect on barley grain yield of four genotypes tested in seven environments and total sum of squares explained $73.9 \%$ for environmental effects, only $6.7 \%$ for genotypic effects and 13.4\% GEI effects (Table 3 and Table 4).

Table 3. The variance of AMMI analysis on grain yield of barley

\begin{tabular}{|c|r|r|r|r|c|c|}
\hline $\begin{array}{c}\text { Resource of } \\
\text { Variance }\end{array}$ & d f & S S & M S & F value & $\begin{array}{l}\text { G+E+GE SS } \\
\text { Explained (\%) }\end{array}$ & $\begin{array}{c}\text { GE SS } \\
\text { Explained (\%) }\end{array}$ \\
\hline Genotypes & 3 & 15565774 & 5188591 & $27.01^{* *}$ & 6.4 & \\
\hline Environments & 6 & 193613612 & 32268935 & $38.41^{* *}$ & 79.4 & \\
\hline Block(E) & 21 & 17643631 & 840173 & $4.37^{* *}$ & & \\
\hline GEI & 18 & 33637083 & 1868727 & $9.73^{* *}$ & 13.9 & \\
\hline IPCA1 & 8 & 22649095 & 2831137 & $14.74^{* *}$ & & 75.2 \\
\hline IPCA2 & 6 & 7452485 & 1242081 & $6.47^{* *}$ & & 24.8 \\
\hline Residuals & 4 & 3535503 & 883876 & $4.60^{*}$ & & \\
\hline Error & 63 & 12100702 & 192075 & & & \\
\hline Total & 111 & 272560801 & 2455503 & & & \\
\hline
\end{tabular}

df, degrees of freedom; SS, sum of squares; MS, mean square. **, $\mathrm{p}<0.01$; G, Genotypes; E, Environments

The high addition of environment effects showed that there were important differences among environments for grain yield. On the other hand, the GEI effect were high than $G$ effect. Moreover, Bantayehu (2013) reported 75.24\%, 
9.32\% and 15.44\%, Rezene (2014), reported 89.6\%, 1.8\% and 8.6\%. Yan and Rajcan (2002), reported the environment effect had the highest effect than other factors on soybean yield.

Table 4. The average yield performance at each $\mathrm{E}$ and over environments $\left(\mathrm{kg} \mathrm{ha}^{-1}\right)$

\begin{tabular}{|l|r|r|r|r|r|r|r|r|}
\hline Cultivars & \multicolumn{1}{|c|}{ E1 } & \multicolumn{1}{c|}{ E2 } & \multicolumn{1}{c|}{ E3 } & \multicolumn{1}{c|}{ E4 } & E5 & \multicolumn{1}{c|}{ E6 } & \multicolumn{1}{c|}{ E7 } & Mean \\
\hline Şahin 91 & 3990 & 4710 & 4650 & 2303 & 3763 & 3603 & 480 & 3357 \\
\hline Candidate & 6440 & 5690 & 5010 & 3090 & 4873 & 3556 & 1810 & 4266 \\
\hline Altıkat & 5990 & 5310 & 6030 & 1950 & 3180 & 3333 & 1588 & 4074 \\
\hline Sur 93 & 3870 & 5020 & 3960 & 2970 & 3405 & 4291 & 1658 & 3450 \\
\hline Mean & 5073 & 5181 & 4909 & 2578 & 3805 & 3696 & 1384 & \\
\hline CV(\%) & 9.3 & 9.68 & 9.66 & 1.38 & 1.93 & 21.59 & 3.86 & \\
\hline
\end{tabular}

The existence of interaction displayed by GGE biplot, especially when the interaction portioned between two interaction principal component axis (IPCA). (Table 3).The obtained data from confirm adequacy to the GGE biplot (Kilic, 2014). The results of mean square of the PCA 1 and PCA 2 interaction axis showed that there is significant $(\mathrm{p}<0.01)$. Results of GGE biplot analysis also indicated that the PCA 1 axis accounted 48.9\%, and the second accounted for $37.4 \%$. The total of IPCA1 and IPCA2 accounted for $86.3 \%$ (Figure 2). GGE biplot showed existence interactions of $\mathrm{G} x \mathrm{E}$, so it was portioned between first and second IPCA (Interaction Principal Component Axes). The barley grain yield variation is depending on genotypic and environment factors as shown Table 1 and Table 2. For interpretation of AMMI, size and signal scores of the IPCA1 were observed, score near to zero were typical of genotypes and environments, which contribute little to the interaction that is they are stable (Tarakanovas and Ruzgas 2006). The AMMI 1 model showing Genotype x Environment means: In the AMMI model, $\mathrm{x}$ axis represents the genotypes and environment main effect and $y$ axis represents the effects of interaction (Figure 1).

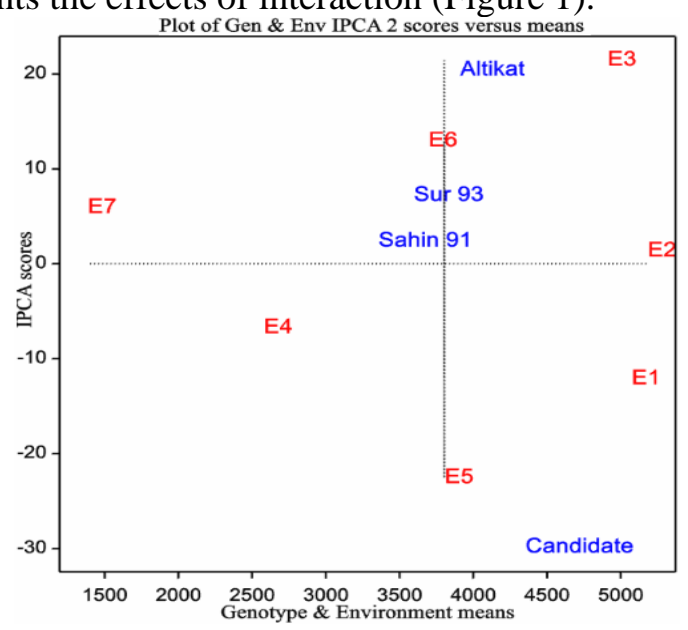

Figure 1. The AMMI 1 model showing grain yield (kg/ha-1) of genotypes(G) in 7 environments(E). 
The environment and genotypes indicated much more variability in both main effect and interaction. According to AMMI, E1, E2, E3 and Candidate, Altikat showed good performance, because of they took place above on axis (mean yield). It is believed that these genotypes and environments were high yielding. On the other hand, E7, E4, E6 and Sur 93 and Sahin 93 demonstrated low performance, due to they located under on axis (mean yield). So, these cultivars and environments which located under on axis (mean yield) were low yielding. The environment E5 only located mean axis. Moreover, E2 had both high yield potential and stabile environment, E1 and E3 had high yield potential, but unstable environments. Candidate line had high yield potential, but unstable, while Sahin 91 was stabile, but low yield potential. E2 could be recommended to tested genotypes with high potential and IPCA values (Table 5), while E7 is not to be recommended to tested genotypes because of low yield potential. Similar outputs were reported by Mohhamadi et al. (2013), in barley.

The recommendation of environment: The average grain yield of seven environments ranged from $1384 \mathrm{~kg} / \mathrm{ha}$ to $5181 \mathrm{~kg} / \mathrm{ha}$ of spring barley genotypes (Table 5).

Table 5. AMMI selections the first four genotypes for per environment and IPCA scores.

\begin{tabular}{|c|c|c|c|c|c|c|c|c|c|}
\hline Sites & Mean & Score & 1 & 2 & 3 & 4 & IPCAe-1 & IPCAe-2 & Variance \\
\hline E1 & 5073 & 22.77 & Candidate & Altikat & Sahin 91 & Sur 93 & -32.13 & -12.16 & 1772 \\
\hline E2 & 5181 & 19.16 & Candidate & Altikat & Sur 93 & Sahin 91 & 0.401 & 1.31 & 2952 \\
\hline E3 & 4909 & 6.39 & Altikat & Candidate & Sahin 91 & Sur 93 & -20.19 & 21.42 & 8236 \\
\hline E4 & 2578 & 3.60 & Candidate & Sur 93 & Sahin 91 & Altikat & 19.16 & -6.77 & 2398 \\
\hline E5 & 3805 & 0.40 & Candidate & Sur 93 & Sahin 91 & Altikat & 6.39 & -22.58 & 4548 \\
\hline E6 & 3695 & -20.19 & Sur 93 & Candidate & Sahin 91 & Altikat & 22.77 & 12.90 & 1377 \\
\hline E7 & 1384 & -32.13 & Candidate & Altikat & Sur 93 & Sahin 91 & 3.60 & 5.88 & 2993 \\
\hline
\end{tabular}

Rank.. = Ranked

The AMMI analysis indicated that the E2 was the best yielding among test environments, followed E2 and E3.On the other hand, E7 was the lowest yielding for among test environments, because of the very low rainfall of this environment. According to results of AMMI analysis showed that we can recommend the E2 to describe the top yield of genotypes, while E7 for drought (Figure1).

Ranking genotypes based on which wins where or which is best for what: The ideal genotype should have high mean performance coupled with high stability to give wide adaptability in the across environments, as showed in Figure 2. The single-arrowed line called average- environment coordination abscissa (or AEA) points to higher mean yield through the environments, the double-arrow line is the AEC ordinate points the average yield of genotypes and environments(Yan and Tinker, 2006). 


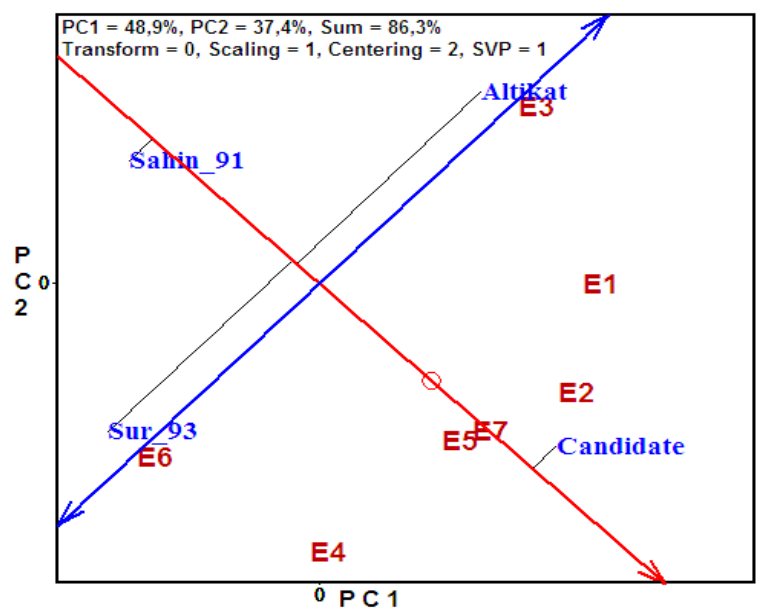

Figure 2. Ranking genotypes based on which wins where or which is best for what

Thus, Candidate line with short genotype vector had both the highest mean yield and stability values, while Sahin 91 had low mean yield through all environment, but stable. On the other hand, Altikat and Sur 93 with longest vector had both low mean yield and unstable values. The results of this study showed that Candidate had wide adaptability for across environments, while Sahin 91 for none, and also Altikat just for E3, Sur 93 for E6. The AEC ordinate split cultivars with above mean and from below means. The Candidate line can be released because of above average mean performance and stability (Fig. 2).

Mega environments "which-won-where" pattern to identify the best genotypes in each environment

Dividing the target environment into meaningful mega-environments and deploying different cultivars for different mega-environments is the only way to utilize positive GE and avoid negative GE and the sole purpose for genotype by environment interaction analysis (Yan et al., 2000 ). A mega-environment is defined as a group of environments that consistently share the same best cultivar(s) (Yan and Rajcan, 2002).

This definition explain the following biplot based on the multienvironment trials (MET) data of barley yield illustrates two points: 1) A megaenvironment may have more than one winning cultivar (sector 1), and 2) even if there exists a universal winner (Candidate), it is still possible, and beneficial, to divide the target environments into meaningful mega-environments (Fig 3).Mainly, these three lines divide the biplot into four sectors. Five environments with Candidate line (E1, E2, E4, E5, E7) down in the sector1, Altikat and E3 in sector2, Sur 93 and E6 in sector4, while only Sahin 91 in sector3. Consequently, Candidate line had high yielding at five environments (E1, E2, E4, E5, E7), while Altikat at E3, Sur 93 at E6. Jalata (2011), reported that favorable genotypes were more discriminating and representative of across environments. 


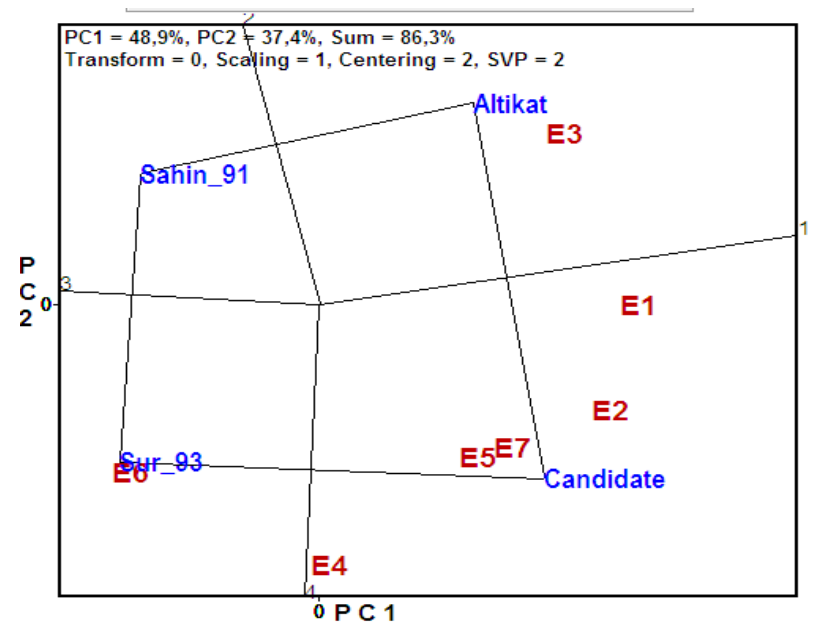

Figure 3. The which-won-where view of the GGE biplot

The performance of each cultivar at each environment: Both the genotype vectors and the environment vectors are drawn in Fig. 4 so that the specific interactions between a genotype and an environment (i.e., the performance of each genotype in each environment) can be visualized. Figure 4 can be used (1) to rank the genotypes based on performance in any environment, and (2) to rank environments on the relative performance of any genotype(Yan and Tinker, 2006). When the angle between two genotypes is $>90^{\circ}$, then this two genotype are different on their genetic. Therefore, Candidate, new variety (Altikat), old varieties (Sur 93 and Sahin 91) are quite different in their genetic make-up with respect grain yield. Because these genotypes took places of different area on biplot and the cosine of vector is obtuse angle for genotypes far from each other. Candidate line has above average (acute angles) for five environments (E1, E2, E4, E5, E7), whereas Sur 93 and Sahin 91 for E6, Altikat for E3.

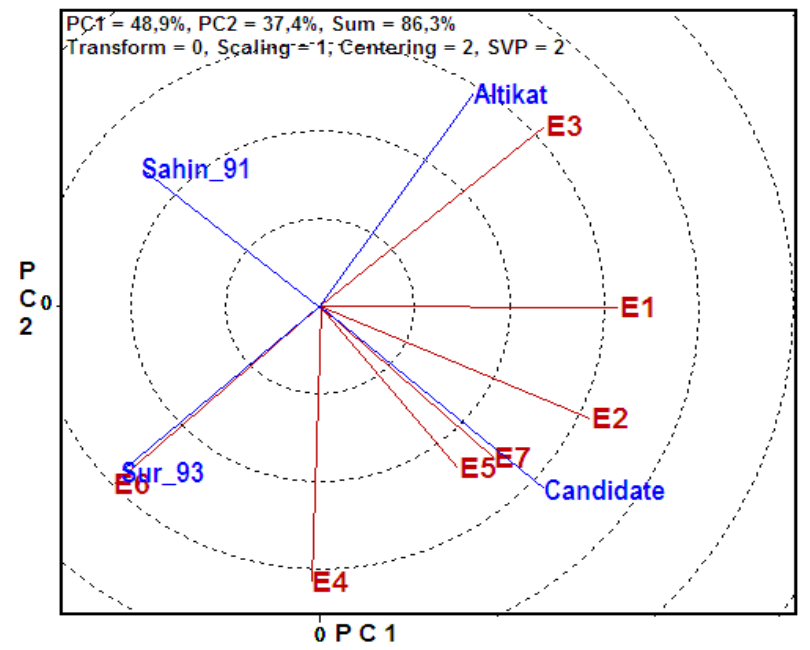

Figure 4. GGE biplot showing the performance of each cultivar at each environment 
The cultivar which located near to the biplot center have less contribution to $G$ or GE, while cultivars having longer vectors show the most contribution of $\mathrm{G}$ and/or GE (Yan and Tinker, 2006). So, Candidate line with the longest vectors is the best genotypes, while other cultivars have short vector than Candidate line. Candidate line can be considered as the best genotype as its vector took place of across environments. Therefore, there is major contribution of $G$ to genotypes for grain yield; because of they have opposite direction, so they can make up different genetic contribution (Jalata, 2011).

Ranking environments based on mean and instability: The genotype, has both high mean yield and high stability is called a ideal genotype. It should have both high mean performance and high stability across environments (Fig.5).

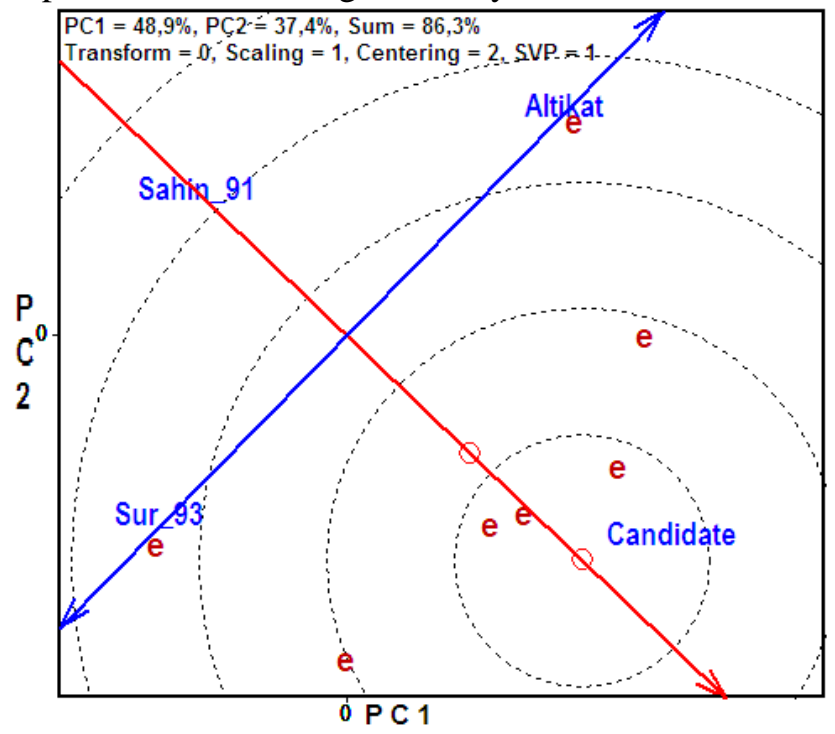

Figure 5.Ranking environments based on mean and instability

The genotypes took places closer to the 'ideal genotype' are more desirable than others (Yan and Tinker, 2006). Therefore, genotypes located closer to the 'ideal genotype' are more desirable than others (Farshadfar et al., 2013). Thus, Candidate line located center of AEA ("absolutely stable") is more desirable than other cultivars lower average yield. Sahin 91 is the poorest cultivar because it is consistently the poorest. According to Fig. 5, Candidate line is highly "stable". Altikat and Sur 93 is poor cultivars, because of they have lower averages yield and just yielding for specific environment. On the other hand, Sahin 91 is even poorer cultivar, because of it is not suitable for any environment and lowest average yield. From this example, we can release this candidate line and recommendation to these environments which involved in the study.

Probability of difference between Candidate line and other cultivars: Any two genotypes can be visually checked by linking them with a flat line, followed by illustration a vertical line that transitions overall the biplot origin by GGE biplot. This vertical line is the "balance line" of the two genotypes. If any 
genotype is higher values in any environment, this genotype locate on its equality line (Yan and Thinker 2006). The following explication can be made based on "Fig. 6". The interaction is not significant $(\mathrm{P}<=0.1898)$ between candidate, Sur 93. Whereas the interaction is significant $(\mathrm{P}<=0.0074)$ between candidate and Sahin 91. Probability of difference between Candidate and old cultivar (Sahin 91) is shown in "Figure 6". The cultivar Sahin 91 had only higher yield in E6, whereas Candidate line had higher yield in other six environments. The biplot distance of the line that linkage the two any genotypes measures the Euclidian distance between them.

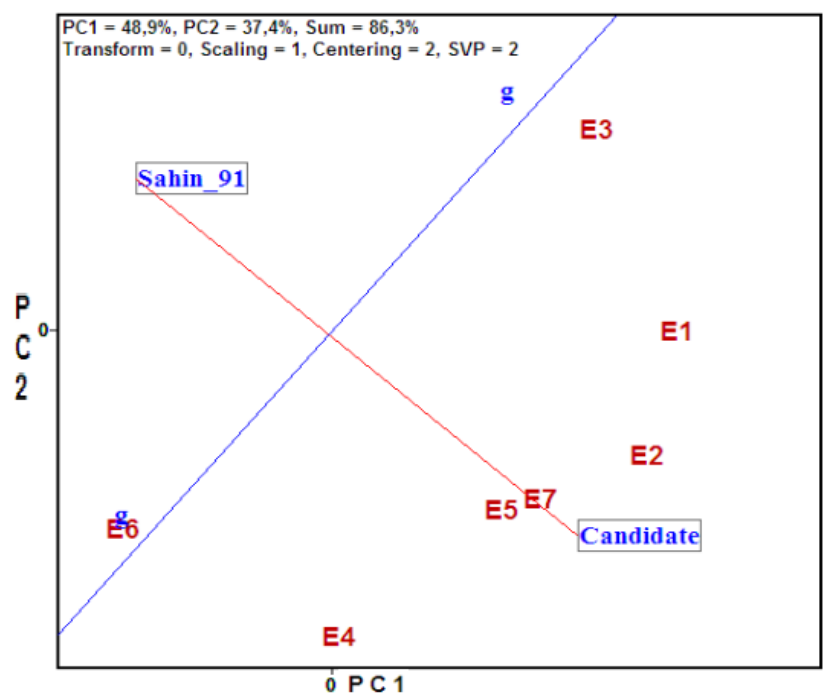

Figure 6. Probability of difference between Candidate and old cultivar (Sahin 91)

If the connection line is long enough, comparison of two genotypes can be use (Yan and Tinker, 2006). The connection line between candidate line and other cultivars in the study was enough long. Therefore the compare of candidate line and other cultivars had good results to recommendation candidate for across environments. The differences between the two genotypes vary by environment. This may be due to the difference in rainfall, temperature, maturity time. This report has been showed by smilar Jalata, (2011) rainfall, temperature, maturity, disease which had important affect on yield and high contribution to GEI.

The relationship genotype by trait(quality) in seven environments: The relationship genotype by trait in seven environments showed in "Table 6 and Fig.7”. A genotype by trait biplot can help understand the relationships among traits (breeding objectives) and can help identify traits that are positively or negatively associated, traits that are redundantly measured, and traits that can be used in indirect selection for another trait. It also helps to visualize the trait profiles (strength and weakness) of genotypes, which is important for parent as well as variety selection (Yan and Tinker, 2006).

The biplot showed that there were positive correlation (the angel of vectors $<90^{\circ}$ ) among PC, TGW, HW and SA, whereas negative correlation (the angel of 
vectors $>90^{\circ}$ ) with LS and this four traits. Also, the relationship between genotypes and traits were observed. Therefore, Sur 93 associated with PC, TGW, HW and SA, while Sahin 91 with PC and TGW, Altikat with LS, Candidate with HW and SW with TGW. Because of the genotypes were positioned on these traits. Consequently, the biplot showed excellent discriminating to select special genotypes with special traits and release candidate line and to recommendation (Abbasian et al., 2014).

Table 6 . The quality traits value of aaverage for four genotypes.

\begin{tabular}{|l|c|c|c|c|c|}
\hline Genotypes & $\begin{array}{c}\text { Hectoliter } \\
\text { weight } \\
(\mathrm{g} / \mathrm{l})\end{array}$ & $\begin{array}{c}\text { Thousand } \\
\text { grain weight } \\
(\mathrm{g})\end{array}$ & $\begin{array}{c}\text { Protein } \\
\text { content } \\
(\%)\end{array}$ & $\begin{array}{c}\text { Sieving } \\
\text { above } \\
(\%)\end{array}$ & $\begin{array}{c}\text { Sieving } \\
\text { lower } \\
(\%)\end{array}$ \\
\hline Şahin 91 & 63.5 & 39.0 & 15.0 & 51.6 & 12.0 \\
\hline Candidate & 66.5 & 36.2 & 13.7 & 78.5 & 4.1 \\
\hline Alt1kat & 61.5 & 29.8 & 13.3 & 44.9 & 16.9 \\
\hline Sur 93 & 65.5 & 40.9 & 15.0 & 77.4 & 4.7 \\
\hline Mean & 64.2 & 36.5 & 14.3 & 63.1 & 9.4 \\
\hline
\end{tabular}

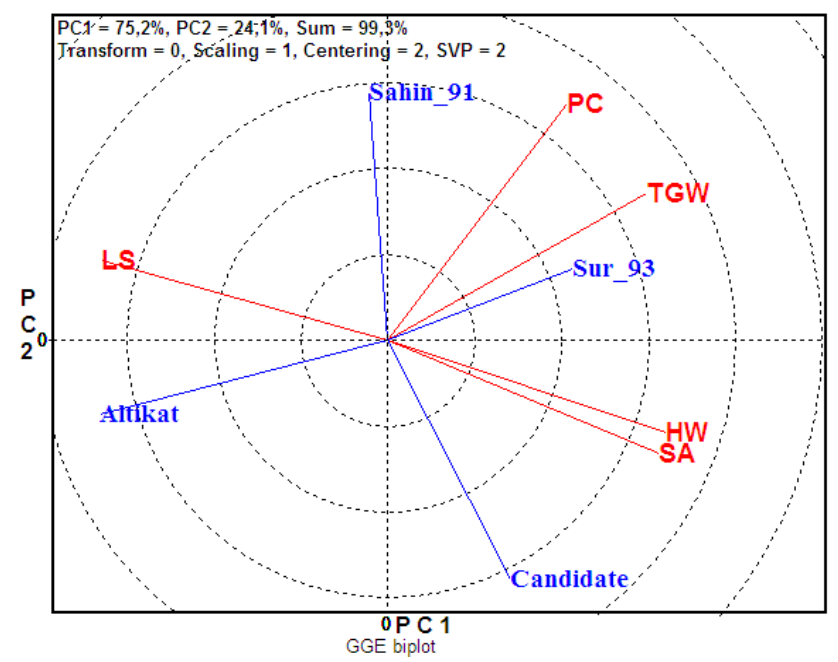

Figure 7. The relationship genotype by trait in seven environments

The relationship between environments by trait (quality) of four genotypes: The relationship between environment-trait showed in Table 7 and Fig. 8. The traits-by environment figure for one trait or averaged across environments can be generated and studied using biplots (Yan and Tinker, 2006).

The biplot showed that there were positive correlation (the angel of vectors $<90^{\circ}$ ) among TGW, HW, SA and between PC and LS, whereas negative correlation (the angel of vectors $>90^{\circ}$ ) between PC, LS and TGW, HW, SA. Also, the relationship among environments and traits were observed. The biplot showed that there were positive correlation (the angel of vectors $<90^{\circ}$ ) among E2, E3, E4 and between E5, E6, whereas negative correlation (the angel of vectors $>90^{\circ}$ ) between the first group (E2, E3, E4) and second group (E5, E6). 
Table 7. The quality traits value of average over environments.

\begin{tabular}{|c|c|c|c|c|c|}
\hline Environments & $\begin{array}{c}\text { Hectoliter } \\
\text { weight } \\
(\mathrm{g} / \mathrm{l})\end{array}$ & $\begin{array}{c}\text { Thousand } \\
\text { grain weight } \\
(\mathrm{g})\end{array}$ & $\begin{array}{c}\text { Protein } \\
\text { content } \\
(\%)\end{array}$ & $\begin{array}{c}\text { Sieving } \\
\text { above } \\
(\%)\end{array}$ & $\begin{array}{c}\text { Sieving } \\
\text { lower } \\
(\%)\end{array}$ \\
\hline E1 & 64.1 & 41.0 & 12.1 & 76.2 & 2.9 \\
\hline E2 & 64.1 & 41.0 & 12.1 & 76.2 & 2.9 \\
\hline E3 & 66.9 & 41.4 & 11.1 & 81.3 & 1.6 \\
\hline E4 & 62.2 & 39.2 & 13.0 & 69.6 & 3.5 \\
\hline E5 & 59.6 & 31.2 & 16.3 & 40.9 & 19.7 \\
\hline E6 & 64.7 & 38.4 & 14.6 & 66.2 & 10.0 \\
\hline E7 & 68.5 & 32.8 & 14.4 & 74.2 & 3.1 \\
\hline Mean & 64.3 & 37.9 & 13.4 & 69.2 & 6.2 \\
\hline
\end{tabular}

Therefore, E3 associated with TGW, HW, SA, while E6 with PC and Altikat with LS. Because of these environments were positioned on definite traits. Consequently, the biplot showed excellent discriminating to select special environment with special traits and to work candidate line for recommendation special traits (Kendal and Sener, 2015).

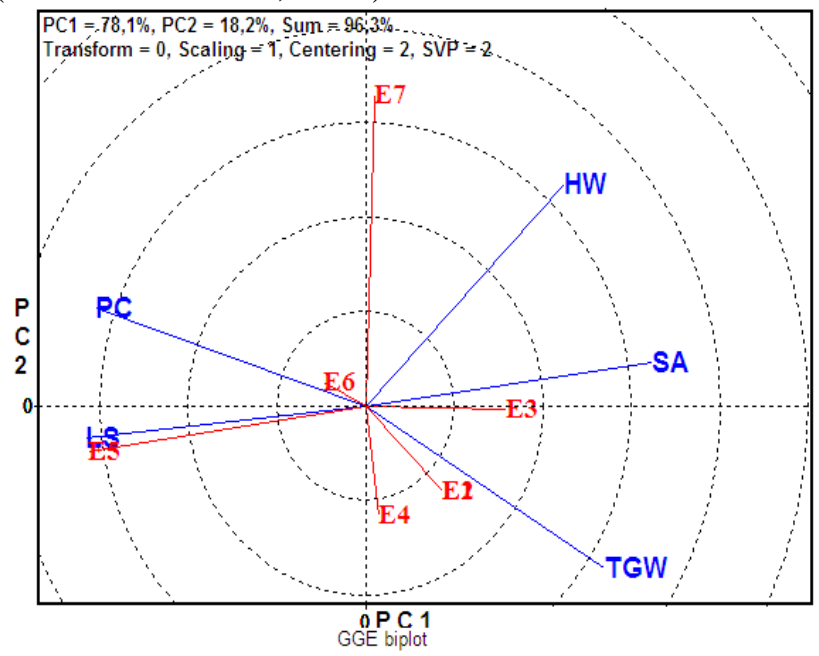

Figure 8. The relationship environment by trait of four genotypes

\section{CONCLUSIONS}

The results indicated that yield performance of barley cultivars were highly influenced by environment followed GE interaction effect and genotype with the least effects. Because of the changing the conditions of environments, the magnitude of environment effect was very high than that of genotype effect. The Candidate line showed best performance among genotypes tested across environments, while the oldest cultivar (Sahin 91) had least grain yield and adaptability. So, the Candidate line was desirable in terms of high mean yield and stability, this means that the study provided an indication of the genetic progress. According to the results, the specific cultivar was appropriate for specific environment (Sur 93-E6, Altikat-E3, Candidate-E1, E2, E4, E5 and E7) and E2 
was the best yielding, while E7 least. As a results indicated that Candidate line can be registered and to recommendation for environments, involved in the study.

\section{REFERENCES}

Abbasian, A., Mohaddesi, A., Amınpanah, H., Ghasemi S M S., Javadi, M and Ebrahimian M. (2014). Evaluation of rice cultivars in different irrigation treatments based on sensitive and tolerance indices. Agriculture and Forestry, Vol. 60. Issue 2: 251-259, 2014, Podgorica

Akter, A., Hassan M, J., Kulsum M, U., Islam, MR., Hossain, K and Rahman M, M. (2014). AMMI biplot analysis for stability of grain yield in hybrid rice J. Rice Res 2:126.

Bantayehu, M., Esmael, J. and Awoke Y. (2013).Additive main effect and multiplicative interaction analysis and clustering of environments and genotypes in malting barley. African Journal of Agricultural Research Vol. 8(18), pp. 1896-1904.

Farshadfar E, Mohammadi R, Aghaee M, Vaisi Z. (2012). GGE biplot analysis of $\mathrm{G} \times \mathrm{E}$ interaction in wheat-barley disomic addition lines. AJCS 6(6):1074-1079.

Gabriel KR (1971). The biplot graphic display of matrices with application to principal component analysis. Biometrika 58: 453-467.

Gauch, HG. (1988). Model selection and validation for yield trials with interaction. Biometrics 44,705-715.

Jalata Z. (2011). GGE-biplot Analysis of Multi-environment yield trials of barley genotypes in Southeastern Ethiopia Highlands. Int. J. of P. B. and Genetics 5(1):59-75.

Kendal, E. and O. Sener. (2015). Examination of genotype $\times$ environment interactions by GGE Biplot analysis in spring durum wheat. Indian J. Genet. Plant. Breed., 75(3): 341348.

Kilic H. (2014). Additive main effect and multiplicative interactions (AMMI) Analysis of grain yield in barley genotypes across environments. Jor. of Agr. Sci.20, 337-344.

Mohammadi, M., Karimizadeh, R., Noorinia, A A., Ghojogh, H., Hosseinpour, T., Khalilzadeh, GR., Mehraban, A., Roustaii, M., Hasanpor Hosni M. (2013). Analysis of yield stability in multi-environment trials of barley (Hordeum vulgare L.) genotypes using AMMI model. Current Opinion in Agriculture Curr. Opin. Agric. 2(1), 20-24.

Rezene, Y. (2014). GGE and AMMI biplot analysis for field pea yield stability in SNNPR state Ethiopia. International Journal of Sustainable Agr.l Research. 1(1):28-38.

Sabaghnia, N., Mohammadi, M and Karimizadeh, R. (2012). The evaluation of genotype $x$ environment interactions of durum wheat's yield using of the AMMI model. Agriculture \& Forestry, Vol. 55. (09) (1-4): 5-21, 2012, Podgorica

Sayar, M.S., Han, Y.2015. Determination of seed yield and yield components of grasspea (Lathyrus sativus L.) lines and evaluations using GGE Biplot analysis method. Tarım Bilimleri Dergisi- Journal Agric. Sci,, 21(1): 78-92.

Tarakanovas, P and Ruzgas V. (2006). Additive main effect and multiplicative interaction analysis of grain yield of wheat varieties in Lithuania. Agr. Research. 4(1):91-98.

Yan W L, Hunt A, Sheng Q \& Szlavnics Z (2000). Cultivar evaluation and mega-environment investigation based on the GGE biplot. Crop Sci. 40: 597-605.

Yan, W. and Rajcanw, I. (2002). Biplot analysis of test sites and trait relations of soybean in Ontario, Crop Science 42. 11-20.

Yan, W., \& Tinker, N.A. 2006. 'An Biplot analysis of multi-environment trial data; Principles and applications, Canadian Journal of Plant Science 86, 623-645. 